\title{
Donepezil for dementia with Lewy bodies: a randomized, placebo-controlled, confirmatory phase III trial
}

\author{
Manabu Ikeda ${ }^{1 *}$, Etsuro Mori $^{2}$, Kazutaka Matsuo ${ }^{3}$, Masaki Nakagawa $^{3}$ and Kenji Kosaka ${ }^{4}$
}

\begin{abstract}
Introduction: The efficacy of a cholinesterase inhibitor, donepezil, in patients with dementia with Lewy bodies (DLB) was investigated to confirm the superiority over placebo in the 12-week, double-blind phase of this phase III study.

Methods: Patients with probable DLB $(n=142)$ were randomly assigned to placebo or to $5 \mathrm{mg}$ or $10 \mathrm{mg}$ of donepezil administered once daily for 12 weeks. The co-primary endpoints were changes in cognitive function assessed using the Mini-Mental State Examination (MMSE) and behavioral and neuropsychiatric symptoms using the Neuropsychiatric Inventory (NPI-2: hallucinations and fluctuations). The superiority of each active group over placebo was determined with simultaneous statistical significance in both endpoints. Safety evaluations included adverse events (AEs) and the unified Parkinson's disease rating scale (UPDRS) part III.
\end{abstract}

Results: The predefined superiority of donepezil to the placebo was not confirmed in either active group in the primary analysis. MMSE score significantly improved compared to placebo in the $10 \mathrm{mg}$ group (10 mg: 2.2 \pm 0.4 , placebo: $0.6 \pm 0.5$ (mean \pm standard error); $P=0.016$ ). The change in MMSE score in the $5 \mathrm{mg}$ group was not significant $(1.4 \pm 0.5$ (mean \pm standard error); $P=0.232$ ). Although NPI-2 improved compared to baseline in the active groups, the differences from placebo were not significant. Most AEs were mild or moderate. Although the incidence of parkinsonism was slightly higher in the $10 \mathrm{mg}$ group, the change in the UPDRS score was minimal and without a significant difference from the placebo group.

Conclusions: The co-primary endpoints were not achieved in this trial. However, significant improvement in MMSE score was demonstrated with $10 \mathrm{mg}$, but not $5 \mathrm{mg}$, of donepezil. The evaluation of psychiatric symptoms might be affected by advanced education and instructions given to caregivers. Overall, donepezil was well tolerated in patients with DLB. With careful attention on gastrointestinal or parkinsonian symptoms, patients with DLB can safely benefit from treatment with donepezil.

Trial registration: ClinicalTrials.gov Identifier: NCT01278407 (trial registration date: 14 January 2011)

\section{Introduction}

Dementia with Lewy bodies (DLB) is the second most common type of senile dementia following Alzheimer's disease (AD) [1]. The core clinical features of DLB are fluctuating cognition, visual hallucinations and motor symptoms of parkinsonism, as well as cognitive impairment characterized by deficits in attention, executive function and visual perception [2]. Other features include neuropsychiatric symptoms such as delusions and depression,

\footnotetext{
* Correspondence: mikeda@kumamoto-u.ac.jp

1 Department of Neuropsychiatry, Faculty of Life Sciences, Kumamoto

University, 1-1-1 Honjo, Chuo-ku, Kumamoto 860-8556, Japan

Full list of author information is available at the end of the article
}

as well as autonomic dysfunction. Fluctuating cognition, hallucinations and delusions impose particular challenges and distress on both patients and caregivers. The motor and autonomic features have a further negative impact on activities of daily living and quality of life [3,4].

DLB is associated with a greater loss of cholinergic neurons in the nucleus basalis of Meynert and lower choline acetyltransferase (ChAT) activity than AD, but more postsynaptic muscarinic receptors in the cortex are preserved [5-7]. The cholinergic depletion correlates not only with the cognitive impairment but also with psychiatric symptoms such as hallucinations [8]. On the

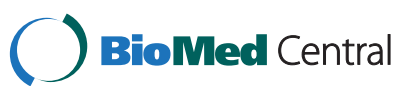

(c) 2015 Ikeda et al.; licensee BioMed Central. This is an Open Access article distributed under the terms of the Creative Commons Attribution License (http://creativecommons.org/licenses/by/4.0), which permits unrestricted use, distribution, and reproduction in any medium, provided the original work is properly credited. The Creative Commons Public Domain Dedication waiver (http://creativecommons.org/publicdomain/zero/1.0/) applies to the data made available in this article unless otherwise stated. 
basis of these pathological features, it has been suggested that cholinesterase inhibitors (ChEIs) may be an effective treatment for DLB $[9,10]$. However, no ChEIs have been approved for DLB to date.

Previously, we examined the efficacy and safety of donepezil administered at 3,5 and $10 \mathrm{mg}$ for 12 weeks in patients with DLB in a placebo-controlled, double-blind exploratory study [11]. An open-label, long-term extension study was then conducted in patients who had completed the double-blind study to examine the safety and efficacy of donepezil at $5 \mathrm{mg}$ for 52 weeks [12]. The double-blind study showed that donepezil at $5 \mathrm{mg}$ or $10 \mathrm{mg}$ per day significantly improved cognitive impairment, behavioral and psychiatric symptoms, global clinical symptoms and the caregiver burden compared to placebo. The longterm study showed that donepezil at $5 \mathrm{mg}$ /day was well tolerated and that it sustained improvement in cognitive impairment and psychiatric symptoms over the course of 52 weeks.

The aim of the present phase III study, integrating a placebo-controlled, double-blind comparative study and an open-label long-term extension study, was to further evaluate the efficacy and to confirm the superiority of donepezil administration at $5 \mathrm{mg}$ and $10 \mathrm{mg}$ per day for 12 weeks over placebo, as well as to evaluate the safety and efficacy of long-term administration at $10 \mathrm{mg}$ as well as $5 \mathrm{mg}$ per day, in patients with DLB. This report describes the results of the placebo-controlled, doubleblind, 12-week phase. Detailed results of the extension phase are reported elsewhere [13].

\section{Methods}

\section{Patients}

Patients diagnosed as probable DLB according to the consensus diagnostic criteria [2] were recruited from 72 psychiatric or neurological specialty centers throughout Japan from February 2011 to March 2012. Eligible patients were outpatients aged $\geq 50$ years with mild to moderate or severe dementia (10 to 26 on the Mini-Mental State Examination (MMSE) and Clinical Dementia Rating $\geq 0.5$ ) and behavioral and psychiatric symptoms (Neuropsychiatric Inventory-plus (NPI-plus) $\geq 8$ and NPI (NPI-2) $\geq 1$ ). The NPI-plus consisted of 12 items: the original 10 items, sleep [14,15] and cognitive fluctuation, which is reported as the Cognitive Fluctuation Inventory $[16,17]$ (see Additional file 1). The NPI-2 consisted of hallucinations and cognitive fluctuation [11]. The caregivers of the eligible patients had to routinely stay with them at least 3 days per week and 4 hours per day, provide information for this study, assist with the compliance with treatment and escort them to required visits.

The exclusion criteria included Parkinson's disease that was diagnosed at least 1 year prior to the onset of dementia; focal vascular lesions visualized on magnetic resonance imaging or computed tomographic scans that might cause cognitive impairment; other neurological or psychiatric diseases; clinically significant systemic disease; complications or a history of severe gastrointestinal ulcer, severe asthma or obstructive pulmonary disease; systolic hypotension $(<90 \mathrm{mmHg})$; bradycardia $\left(<50 \mathrm{~m}^{-1}\right)$; sick sinus syndrome; atrial or atrioventricular conduction block; QT interval prolongation ( $\geq 450 \mathrm{~ms}$ ); hypersensitivity to donepezil or piperidine derivatives; severe parkinsonism (Hoehn and Yahr stage IV or above) [18]; and treatment with ChEIs or any investigational drug within 3 months prior to screening. ChEIs, antipsychotics and antiparkinson drugs other than L-dopa or dopamine agonists were not allowed during the study.

\section{Randomization and masking}

This study consisted of two phases: a 16-week, doubleblind randomized control (RCT) phase and a subsequent 36-week, open-label extension phase. Treatment with donepezil lasted up to 52 weeks in total. The RCT phase, which was preceded by a 2 -week ( 1 to 3 weeks) prerandomization period, entailed the 12-week confirmatory phase (Figure 1). In this article, we report the results of the confirmatory phase. All patients were given placebo tablets during the prerandomization period, after which the patients were assigned in a 1:1:1 ratio to placebo or $5 \mathrm{mg}$ or $10 \mathrm{mg}$ of donepezil in the RCT phase. Randomization was performed centrally according to a dynamic allocation, adjusting for MMSE and NPI-2 scores at screening. A member of the research staff who was in charge of randomization and who was independent of all the parties concerned with the study securely kept the randomization list with limited access only in an emergency. No other members of the research staff, including the physicians, nurses and study institution staff were aware of the treatment assignment, nor were any of the participants.

Patients received two study drug tablets, which were composed of a combination of $3 \mathrm{mg}, 5 \mathrm{mg}$, or the matched placebo tablets with the same physical appearance, once daily in the morning. The dosage was titrated at the beginning. Treatment began with $3 \mathrm{mg}$ for 2 weeks, and then the dose was increased to $5 \mathrm{mg}$. Thereafter, the dose was increased to $10 \mathrm{mg}$ at week 6 only in the $10 \mathrm{mg}$ group. The dose was escalated after patient safety was confirmed. Dose reduction was not permitted in the RCT phase.

\section{Procedures}

In the confirmatory phase, efficacy was assessed at baseline and at weeks 4, 8 and 12 . Co-primary endpoints were cognitive function assessed using the MMSE [19] and behavioral and neuropsychiatric symptoms assessed using the NPI-2 [11], both at week 12. NPI-2 was calculated as the sum of the scores for hallucinations and cognitive 


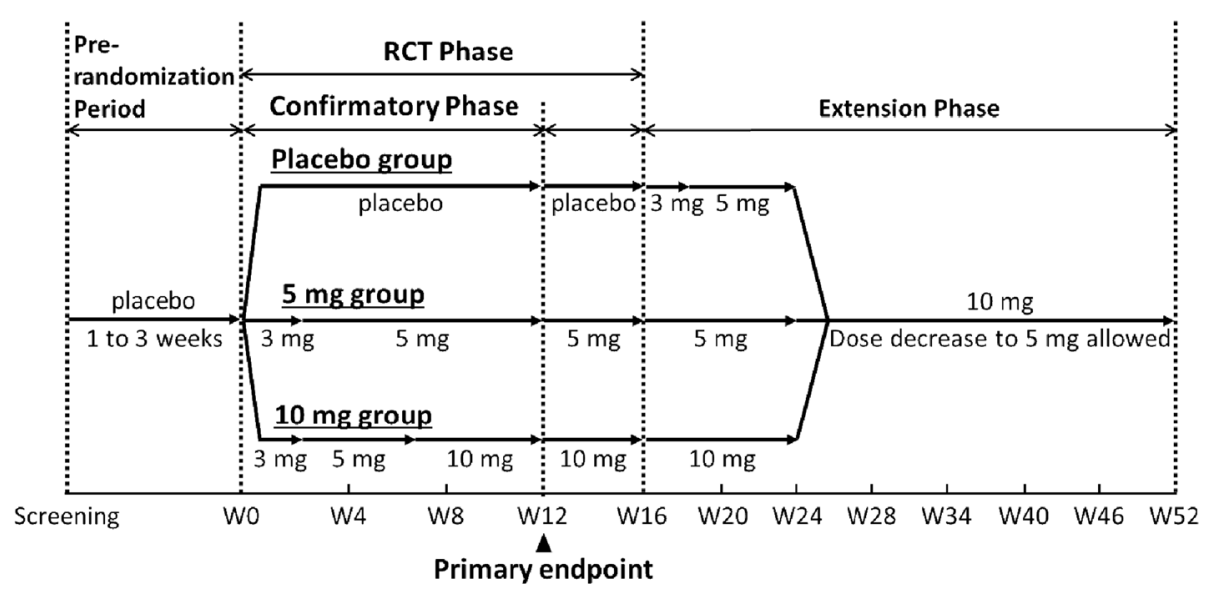

Figure 1 Study flow. RCT, Randomized placebo-controlled trial.

fluctuation, which corresponded to two of the core features of DLB in the consensus criteria. The original NPI-10 (delusions, hallucinations, agitation/aggression, dysphoria, anxiety, euphoria, apathy, disinhibition, irritability/lability and aberrant motor behavior) was set as a secondary endpoint.

Caregiver burden was assessed using the Zarit Caregiver Burden Interview (ZBI) [20], which evaluates the physical, psychological and social consequences of care activities. The ZBI contains 22 items scored from 0 (best) to 4 (worst), from which a total score of 0 to 88 is calculated.

Safety was assessed based on adverse events (AEs), vital signs, electrocardiograms and laboratory tests. All AEs were classified and coded according to Medical Dictionary for Regulatory Activities ("MedDRA") terms. Gastrointestinal symptoms, parkinsonian symptoms, psychiatric symptoms and arrhythmia were assessed as AEs of interest. Motor function was assessed as a safety measure using the Unified Parkinson's Disease Rating Scale (UPDRS) part III [21] at baseline and week 12.

Written informed consent was obtained from the patients (if at all possible) and their primary caregiving family members before initiating the study procedures. The study was conducted in accordance with the principles of the Declaration of Helsinki. The protocol was approved by the institutional review board at each center (Additional file 2).

\section{Statistical analyses}

In a sample size calculation, the mean changes in MMSE score were estimated to be $-0.4,2.0$ and 2.0 with standard deviation (SD) of 3.3 , and the mean changes in NPI-2 score were estimated to be $1.1,-3.3$ and -4.6 with $\mathrm{SD}$ of 5.2 in the placebo, $5 \mathrm{mg}$ and $10 \mathrm{mg}$ groups, respectively, according to the results of the previous double-blind study. The Bonferroni-corrected significance level was set at one-sided $1.25 \%$. Detecting the significant difference, predefined to be determined only with statistical significance in both MMSE and NPI-2 results, with at least $80 \%$ statistical power between the placebo and $5 \mathrm{mg}$ groups required at least 126 patients (42 per group) (statistical power of $80.7 \%$ ). The number was expected to provide power of $85.4 \%$ to detect a significant difference between the placebo and $10 \mathrm{mg}$ groups. Given that $10 \%$ of the patients were excluded from the full analysis set (FAS), the target number of patients in this study was set at 141 .

Efficacy was analyzed in the FAS and the per-protocol set (PPS). Analysis using the FAS was positioned for primary analysis. Mean changes from the baseline in each outcome measure were compared between each active group and placebo by analysis of covariance (ANCOVA) with baseline values as covariates. Only the statistical significance in both MMSE and NPI-2 between the placebo group and each active group could determine the superiority of the active drug over placebo. The significance level was adjusted for multiplicity using the Hochberg method. In addition, MMSE improvement was evaluated by responder rate, defined as the proportion of patients with $\geq 3$-point improvement.

The safety analysis set comprised all patients who received at least one dose and had a postbaseline safety assessment. The incidence of AEs was summarized by group. For laboratory parameters and vital signs, descriptive statistics and frequency distributions were calculated. UPDRS part III scores were compared between each active group and the placebo group using ANCOVA with baseline values as covariates.

All analyses were carried out using SAS versions 9.1 and 9.2 software (SAS Institute, Cary, NC, USA).

\section{Results}

Patients

Of 161 patients enrolled in the prerandomization period, 142 were enrolled in the RCT phase and randomized to 
the placebo, $5 \mathrm{mg}$ and $10 \mathrm{mg}$ groups (46, 47 and 49 patients, respectively) (Figure 2). Of these patients, 138 were included in the FAS (44, 45 and 49 patients in the placebo, $5 \mathrm{mg}$ and $10 \mathrm{mg}$ groups, respectively). Four patients (two patients each in the placebo and $5 \mathrm{mg}$ groups) were excluded because of a lack of evaluable efficacy data (three patients) and doubtful diagnosis of probable DLB (one patient). Excluding 19 patients from the FAS, 119 patients $(40,34$ and 45 patients in the placebo, $5 \mathrm{mg}$ and $10 \mathrm{mg}$ groups, respectively) constituted the PPS. The reasons for the 19 exclusions were discontinuation within $<8$ weeks, compliance rate $<75 \%$ or lack of efficacy data due to a change in the evaluator.

Thirty-one patients discontinued $(9,16$ and 6 patients in the placebo, $5 \mathrm{mg}$ and $10 \mathrm{mg}$ groups, respectively) with more discontinuations in the $5 \mathrm{mg}$ group than in the $10 \mathrm{mg}$ group. The total discontinuations in the active groups comprised 22 (22.9\%) of the 96 patients, which was similar to the placebo group (19.6\%).

Demographic and baseline characteristics of the FAS are summarized in Table 1 . There were no characteristic differences among the three groups. Females accounted for $58.0 \%$. The mean age was 77.9 (range, 57 to 95) years. All but two patients were 65 years of age or older. Dementia medication had previously been used by only $5.8 \%$ of the patients. The mean MMSE score at baseline was 20.4 points.

\section{Co-primary endpoints (MMSE and NPI-2 scores)}

Changes in the co-primary endpoints (MMSE and NPI2 scores) from baseline are shown in Table 2. Primary analysis did not confirm the predefined superiority of either active group to the placebo group.

\section{Cognitive function}

Mean changes from baseline in MMSE in the FAS and PPS are shown in Table 3. In the FAS, the mean change from baseline in the MMSE scores at week 12 (last observation carried forward (LOCF)) was higher in each active group (mean \pm standard error (SE): $1.4 \pm 0.5$ and $2.2 \pm 0.4$ in the $5 \mathrm{mg}$ and $10 \mathrm{mg}$ groups, respectively) than in the placebo group (mean \pm SE: $0.6 \pm 0.5$ ). Improvement in the $10 \mathrm{mg}$ group was significant compared to that in the placebo group (mean difference from placebo $=1.6$; $P=0.016$ ), but that in the $5 \mathrm{mg}$ group was not (mean difference from the placebo $=0.8, P=0.232$ ). PPS analysis yielded a significant improvement in both active groups (5 mg: $P=0.025,10 \mathrm{mg}: P=0.004$ ). The responder rate (MMSE score change $\geq 3$ ) was higher in each active group than in the placebo group (29.5\%, $41.9 \%$ and $42.9 \%$ in the placebo, $5 \mathrm{mg}$ and $10 \mathrm{mg}$ groups, respectively).

\section{Behavioral and neuropsychiatric symptoms}

Changes from baseline in NPI-2 and NPI-10 scores are shown in Table 4 . The changes in NPI-2 scores in both active groups were not significantly different from that in the placebo group. In the active group, NPI-2 improved at week 12 (LOCF) (mean \pm SE: $-1.8 \pm 0.6$ and $-2.8 \pm 0.5$ in the $5 \mathrm{mg}$ and $10 \mathrm{mg}$ groups, respectively). However, the placebo group also showed improvement of $-2.1 \pm 0.6$ $($ mean \pm SE). The NPI-10 score improved at week 12 (LOCF) in each active group by $-3.3 \pm 1.4$ and $-5.5 \pm 1.4$ (mean $\pm \mathrm{SE}$ ) in the $5 \mathrm{mg}$ and $10 \mathrm{mg}$ groups, respectively, and also in the placebo group, by $-6.4 \pm 1.5$. There was no significant difference between either of the active groups and the placebo group.

\section{Caregiver burden}

ZBI score at week 12 (LOCF) was almost unchanged from the baseline in the placebo group (mean \pm SE: $-0.1 \pm 1.8$ ). In both the $5 \mathrm{mg}$ and $10 \mathrm{mg}$ groups, the score improved by $-5.0 \pm 1.8$ and $-0.8 \pm 1.7$ points (mean $\pm \mathrm{SE}$ ), respectively, but without a significant difference from the placebo group. Subgroup analysis yielded a stronger trend of the ZBI improvement in a group of caregivers who lived with the patient, and a significant difference between the $5 \mathrm{mg}$ group and the placebo group (FAS-LOCF: $P=0.017$ ).

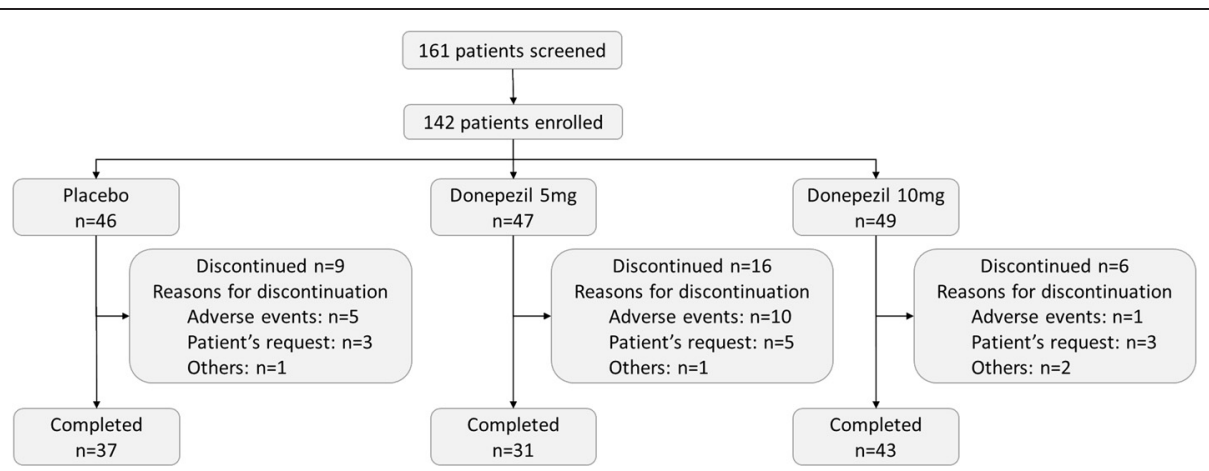

Figure 2 Patient disposition in the confirmatory phase. 
Table 1 Patient demographics and baseline characteristics ${ }^{\mathrm{a}}(\mathrm{FAS}, \mathrm{N}=138)$

\begin{tabular}{|c|c|c|c|c|}
\hline \multirow[b]{2}{*}{ Characteristics } & \multirow[b]{2}{*}{$\begin{array}{l}\text { Placebo } \\
(n=44)\end{array}$} & \multicolumn{2}{|l|}{ Donepezil } & \multirow[b]{2}{*}{$\begin{array}{l}\text { Overall } \\
(n=138)\end{array}$} \\
\hline & & $\begin{array}{l}5 \mathrm{mg} \\
(n=45)\end{array}$ & $\begin{array}{l}10 \mathrm{mg} \\
(n=49)\end{array}$ & \\
\hline \multicolumn{5}{|l|}{ Sex, $n(\%)$} \\
\hline Male & 17 (38.6) & $20(44.4)$ & $21(42.9)$ & $58(42.0)$ \\
\hline Female & $27(61.4)$ & $25(55.6)$ & $28(57.1)$ & $80(58.0)$ \\
\hline Age, yr & $77.2 \pm 6.1$ & $78.8 \pm 5.1$ & $77.7 \pm 6.8$ & $77.9 \pm 6.1$ \\
\hline Weight, kg & $50.15 \pm 10.75$ & $50.68 \pm 9.24$ & $51.72 \pm 9.89$ & $50.88 \pm 9.92$ \\
\hline Duration of dementia, yr & $2.0 \pm 2.3$ & $2.7 \pm 1.8$ & $2.3 \pm 1.9$ & $2.3 \pm 2.0$ \\
\hline \multicolumn{5}{|c|}{ History of anti-dementia medication, $n$ (\%) } \\
\hline Yes & $1(2.3)$ & $3(6.7)$ & $4(8.2)$ & $8(5.8)$ \\
\hline No & $43(97.7)$ & $42(93.3)$ & $45(91.8)$ & $130(94.2)$ \\
\hline \multicolumn{5}{|l|}{ Cognitive fluctuation, $n(\%)$} \\
\hline Yes & $40(90.9)$ & $41(91.1)$ & $46(93.9)$ & $127(92.0)$ \\
\hline No & $4(9.1)$ & $4(8.9)$ & $3(6.1)$ & $11(8.0)$ \\
\hline \multicolumn{5}{|l|}{ Visual hallucinations, $n$ (\%) } \\
\hline Yes & $42(95.5)$ & $39(86.7)$ & 39 (79.6) & $120(87.0)$ \\
\hline No & $2(4.5)$ & $6(13.3)$ & $10(20.4)$ & $18(13.0)$ \\
\hline \multicolumn{5}{|l|}{ Parkinsonism, n (\%) } \\
\hline Yes & $38(86.4)$ & $39(86.7)$ & $44(89.8)$ & $121(87.7)$ \\
\hline No & $6(13.6)$ & $6(13.3)$ & $5(10.2)$ & $17(12.3)$ \\
\hline \multicolumn{5}{|l|}{ Hoehn and Yahr stage, $n$ (\%) } \\
\hline 1 & $4(9.1)$ & $8(17.8)$ & $7(14.3)$ & $19(13.8)$ \\
\hline$\|$ & $15(34.1)$ & $17(37.8)$ & 19 (38.8) & $51(37.0)$ \\
\hline III & $19(43.2)$ & $14(31.1)$ & $18(36.7)$ & $51(37.0)$ \\
\hline MMSE score & $20.3 \pm 4.2$ & $20.6 \pm 4.1$ & $20.3 \pm 4.8$ & $20.4 \pm 4.3$ \\
\hline NPI-2 score & $6.9 \pm 4.5$ & $6.9 \pm 4.5$ & $7.3 \pm 4.7$ & $7.1 \pm 4.5$ \\
\hline NPI-10 score & $20.5 \pm 15.0$ & $18.9 \pm 15.3$ & $16.6 \pm 11.7$ & $18.6 \pm 14.0$ \\
\hline ZBI score & $28.4 \pm 16.2$ & $28.3 \pm 18.5$ & $31.4 \pm 17.8$ & $29.4 \pm 17.4$ \\
\hline
\end{tabular}

${ }^{\mathrm{a}}$ FAS, Full analysis set; MMSE, Mini-Mental State Examination; NPI, Neuropsychiatric Inventory; ZBI, Zarit Caregiver Burden Interview. Values are expressed as mean $\pm S D$, unless otherwise specified.

Table 2 Co-primary endpoints (MMSE and NPI-2 scores) and changes from baseline (FAS LOCF) ${ }^{\text {a }}$

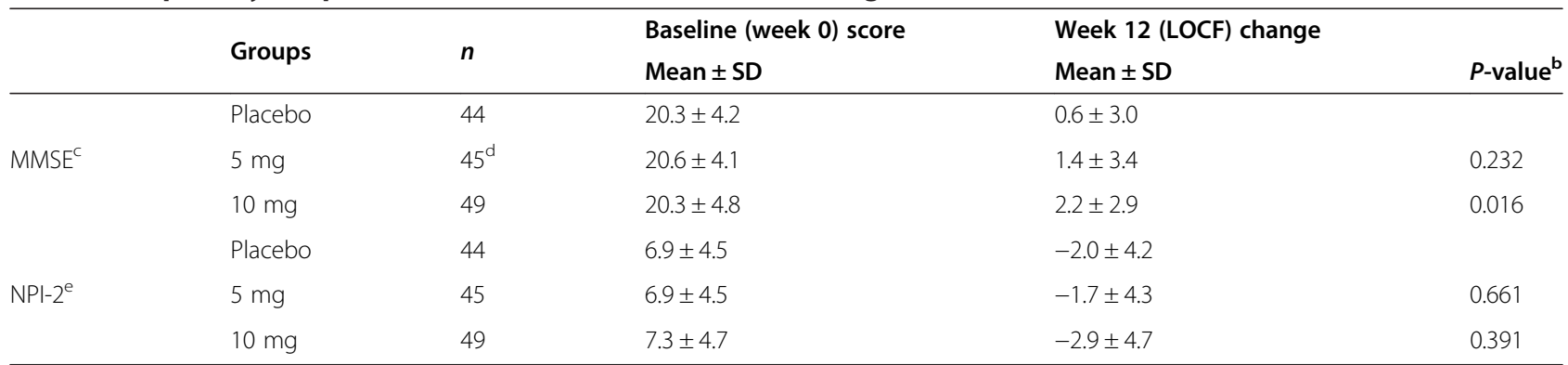

${ }^{\mathrm{a}}$ FAS, Full analysis set; LOCF, Last observation carried forward; MMSE, Mini-Mental State Examination; NPI, Neuropsychiatric Inventory. ${ }^{\mathrm{b}}$ Analysis of covariance with treatment groups as factors and baseline values as covariates. Significance was defined as $P<0.05$. ' $P$ Positive value of the MMSE change indicates an improvement in cognitive function. ${ }^{\mathrm{d}}$ The number of patients at week 12 (LOCF) was 43 . ${ }^{\mathrm{e}} \mathrm{A}$ negative value of the NPI- 2 change indicates an improvement in behavioral and neuropsychiatric symptoms. 
Table 3 Mean changes in Mini-Mental State Examination (MMSE) scores from baseline (LOCF)

\begin{tabular}{|c|c|c|c|c|c|}
\hline & Group & $n$ & Mean $\pm \mathrm{SE}^{\mathrm{b}}$ & Difference from placebo group ${ }^{b}(95 \% \mathrm{Cl})$ & $P$-value \\
\hline & Placebo & 44 & $0.6 \pm 0.5$ & - & - \\
\hline \multirow[t]{3}{*}{ FAS-LOCF } & $5 \mathrm{mg}$ & 43 & $1.4 \pm 0.5$ & $0.8(-0.5,2.1)$ & 0.232 \\
\hline & $10 \mathrm{mg}$ & 49 & $2.2 \pm 0.4$ & $1.6(0.3,2.8)$ & $0.016^{c}$ \\
\hline & Placebo & 37 & $1.0 \pm 0.5$ & - & - \\
\hline \multirow[t]{3}{*}{ FAS-OC } & $5 \mathrm{mg}$ & 32 & $2.2 \pm 0.5$ & $1.2(-0.2,2.7)$ & 0.083 \\
\hline & $10 \mathrm{mg}$ & 43 & $2.6 \pm 0.4$ & $1.6(0.3,2.9)$ & $0.014^{c}$ \\
\hline & Placebo & 40 & $0.5 \pm 0.5$ & - & - \\
\hline \multirow[t]{2}{*}{ PPS-LOCF } & $5 \mathrm{mg}$ & 34 & $2.1 \pm 0.5$ & $1.6(0.2,2.9)$ & $0.025^{c}$ \\
\hline & $10 \mathrm{mg}$ & 45 & $2.4 \pm 0.4$ & $1.9(0.6,3.2)$ & $0.004^{c}$ \\
\hline
\end{tabular}

${ }^{a} \mathrm{Cl}$, Confidence interval; FAS, Full analysis set; LOCF, Last observation carried forward; MMSE, Mini-Mental State Examination; OC, Observed case; PPS, Per-protocol set. 'beast squares mean from analysis of covariance with treatment groups as factors and baseline values as covariates. A positive value of the MMSE change indicates improvement in cognitive function. ${ }^{c} P<0.05$.

\section{Safety}

The incidence of AEs and treatment-related AEs did not differ substantially among the groups (AEs: 67.4\% (31 of 46), $63.8 \%$ (30 of 47 ) and $69.4 \%$ (34 of 49); treatmentrelated AEs: $23.9 \%$ (11 of 46), 25.5\% (12 of 47) and $28.6 \%$ (14 of 49 ) in the placebo, $5 \mathrm{mg}$ and $10 \mathrm{mg}$ groups, respectively). The incidence of severe or serious AEs in either of the active groups (severe AEs: $8.5 \%$ (4 of 47 ) and $0 \%$ (0 of 49); serious AEs: $8.5 \%$ (4 of 47 ) and 2.0\% (1 of 49) in the $5 \mathrm{mg}$ and $10 \mathrm{mg}$ groups, respectively) did not substantially exceed those in the placebo group (severe AEs: 6.5\% (3 of 46); serious AEs: 10.9\% (5 of 46)). The incidence of the AEs that led to discontinuation was higher in the $5 \mathrm{mg}$ group (21.3\% (10 of 47$)$ ), but lower in the $10 \mathrm{mg}$ group (4.1\% (2 of 49$)$ ), than in the placebo group (10.9\% (5 of 46)).

AEs with an incidence $\geq 5 \%$ in any treatment group are shown in Table 5. Major AEs with a higher incidence in either of the active groups than in the placebo group were parkinsonism (4.3\% (2 of 46), 4.3\% (2 of 47) and $8.2 \%$ (4 of 49 ), in the placebo, $5 \mathrm{mg}$ and $10 \mathrm{mg}$ groups, respectively, provided in the same order hereinafter), decreased appetite (2.2\% (1 of 46), 6.4\% (3 of 47), and $4.1 \%$ (2 of 49$)$ ) and nausea (2.2\% (1 of 46 ), 6.4\% (3 of 47 ) and $2.0 \%$ (1 of 49$))$. The incidence of contusion in the active groups $(0.0 \%$ (0 of 47$)$ and $2.0 \%$ ( 1 of 49 ) in the
$5 \mathrm{mg}$ and $10 \mathrm{mg}$ groups, respectively) was low compared to the placebo group ( $8.7 \%$ ( 4 of 46$)$ ).

The incidence of gastrointestinal events in the $5 \mathrm{mg}$ group was higher than in the placebo group, but that in the $10 \mathrm{mg}$ group was similar to the placebo group (13.0\% (6 of 46), 21.3\% (10 of 47) and 14.3\% (7 of 49)). Decreased appetite and nausea were both observed in $>5 \%$ of patients in the $5 \mathrm{mg}$ group, but the incidence of no gastrointestinal events in the $10 \mathrm{mg}$ group reached 5\%. All gastrointestinal events were mild or moderate in severity. When analyzed in 14-day intervals from the baseline, the incidence in the $10 \mathrm{mg}$ group at the interval of days 43 to 56 , the first interval following the dose increase from 5 to $10 \mathrm{mg}$ at week 6 , was the highest among the periods and the groups $(8.3 \%)$.

As parkinsonian AEs, only parkinsonism was reported, and its incidence was slightly higher in the $10 \mathrm{mg}$ group than in the placebo and $5 \mathrm{mg}$ groups (4.3\% (2 of 46), $4.3 \%$ ( 2 of 47 ) and $8.2 \%$ (4 of 49 )), all of which were mild or moderate and not serious. Changes from baseline in the UPDRS part III score were minimal in all of the groups $(-0.9 \pm 0.9,-1.7 \pm 0.9$ and $0.4 \pm 0.9$ points (mean $\pm \mathrm{SE}$ ) respectively) without a significant difference between either of the active groups and the placebo group $(5 \mathrm{mg}$ : $P=0.525,10 \mathrm{mg}: P=0.306)$.

Table 4 Change in NPI from baseline (FAS-LOCF) ${ }^{\mathrm{a}}$

\begin{tabular}{llllll}
\hline & Group & $\boldsymbol{n}$ & Mean $\pm \mathbf{S E}^{\mathbf{b}}$ & Difference from placebo group $\left.\mathbf{~}^{\mathbf{6}} \mathbf{9 5 \%} \mathbf{C l}\right)$ & $\boldsymbol{P}_{\text {-value }}$ \\
\hline \multirow{2}{*}{$\mathrm{NPI}-2$} & Placebo & 44 & $-2.1 \pm 0.6$ & - & - \\
& $5 \mathrm{mg}$ & 45 & $-1.8 \pm 0.6$ & $0.4(-1.3,2.0)$ & 0.661 \\
& $10 \mathrm{mg}$ & 49 & $-2.8 \pm 0.5$ & $-0.7(-2.3,0.9)$ & - \\
$\mathrm{NPI}-10$ & Placebo & 44 & $-6.4 \pm 1.5$ & - & - \\
& $5 \mathrm{mg}$ & 45 & $-3.3 \pm 1.4$ & $3.0(-1.0,7.1)$ & 0.143 \\
& $10 \mathrm{mg}$ & 49 & $-5.5 \pm 1.4$ & $0.9(-3.1,4.9)$ & 0.660 \\
\hline
\end{tabular}

${ }^{\mathrm{a}}$ FAS, Full analysis set; LOCF, Last observation carried forward; NPI, Neuropsychiatric Inventory. ${ }^{\mathrm{b}}$ Least squares mean from analysis of covariance with treatment groups as factors and baseline values as covariates. A negative value of the NPI change indicates an improvement in behavioral and neuropsychiatric symptoms. 
Table 5 Adverse events with an incidence of more than $5 \%$ in any treatment groups ${ }^{a}$

\begin{tabular}{|c|c|c|c|c|c|c|}
\hline \multirow[b]{2}{*}{$\mathrm{AE}$} & \multicolumn{2}{|c|}{ Placebo group $(n=46)$} & \multicolumn{2}{|c|}{$5 \mathrm{mg}$ group $(n=47)$} & \multicolumn{2}{|c|}{10 mg group $(n=49)$} \\
\hline & $\mathrm{AEs}$ & Treatment-related $\mathrm{AEs}^{\mathrm{b}}$ & AEs & Treatment-related $\mathrm{AEs}^{\mathrm{b}}$ & AEs & Treatment-related $\mathrm{AEs}$ \\
\hline Total incidence & $31(67.4)$ & $11(23.9)$ & $30(63.8)$ & $12(25.5)$ & $34(69.4)$ & $14(28.6)$ \\
\hline Nausea & $1(2.2)$ & $1(2.2)$ & $3(6.4)$ & $2(4.3)$ & $1(2.0)$ & $1(2.0)$ \\
\hline Pyrexia & 0 & 0 & 0 & 0 & $3(6.1)$ & 0 \\
\hline Nasopharyngitis & $7(15.2)$ & 0 & $4(8.5)$ & 0 & $2(4.1)$ & 0 \\
\hline Contusion & $4(8.7)$ & 0 & 0 & 0 & $1(2.0)$ & 0 \\
\hline Decreased appetite & $1(2.2)$ & $1(2.2)$ & $3(6.4)$ & $1(2.1)$ & $2(4.1)$ & $2(4.1)$ \\
\hline Parkinsonism & $2(4.3)$ & $2(4.3)$ & $2(4.3)$ & $2(4.3)$ & $4(8.2)$ & $4(8.2)$ \\
\hline Pollakiuria & 0 & 0 & $3(6.4)$ & $3(6.4)$ & 0 & 0 \\
\hline
\end{tabular}

${ }^{\mathrm{a}} \mathrm{AE}$, Adverse event. Incidence shown as number and percentage. ${ }^{\mathrm{b}} \mathrm{AEs}$ for which a causal relationship with the study drug was considered possible or probable.

The incidence of psychiatric events was similar between the $5 \mathrm{mg}$ group and the placebo group, and the incidence in the $10 \mathrm{mg}$ group was lower than that in the placebo group (10.9\% (5 of 46 ), $12.8 \%$ (6 of 47 ) and $4.1 \%$ (2 of 49 )). The incidence of individual psychiatric events was $<5 \%$ in each group. Five severe psychiatric events were reported in two patients in the $5 \mathrm{mg}$ group: visual hallucinations, insomnia, paranoia, agitation and irritability, all of which were judged to be related to the treatment.

The incidence of arrhythmic events was similar among the groups (4.3\% (2 of 46), 4.3\% (2 of 47) and 6.1\% (3 of 49)). Each event was reported by only one patient, and the events were of mild to moderate severity.

For vital signs, blood pressure, pulse rate and body weight slightly declined in the active groups. AEs related to vital signs were ventricular extrasystoles $(n=1)$ and hypotension $(n=1)$ in the $10 \mathrm{mg}$ group and weight decrease $(n=1)$ in the $5 \mathrm{mg}$ group. All of these AEs were either mild or moderate. No patients reported any abnormal changes in pulse rate. The incidences of abnormal changes in the electrocardiogram were similar among the groups (4.7\% (2 of 43), 4.7\% (2 of 43) and 6.3\% (3 of 48$)$ ).

\section{Discussion}

In the primary analysis of the co-primary endpoints (MMSE and NPI-2 scores), predefined superiority over placebo was not confirmed in either the $5 \mathrm{mg}$ or $10 \mathrm{mg}$ group. However, in the evaluation of cognitive function using MMSE score, the difference between the placebo and $10 \mathrm{mg}$ groups was significant, which is consistent with the previous double-blind study [11]. The mean change in the MMSE score in the $10 \mathrm{mg}$ group was 2.2 points, which was almost equal to the score of 2.3 obtained in our previous study [11].

The improvement in the $5 \mathrm{mg}$ group was found to be significant only in the PPS analysis, although it was also found to be significant in all analyses in the previous study [11]. The results of the present study did not replicate our previous finding, which is probably due to a relatively larger number of earlier discontinuations. In the $5 \mathrm{mg}$ group, eight patients (17.0\%) discontinued by week 4 when the blood concentrations of $5 \mathrm{mg}$ donepezil reached the steady state, whereas only one patient $(3.0 \%)$ discontinued in the previous study. The imbalance of discontinuation was not caused by the dose of $5 \mathrm{mg}$ itself, because only one patient in the $10 \mathrm{mg}$ group discontinued by week 4 , while taking the same doses as the $5 \mathrm{mg}$ group until week 6 .

In two phase III studies in which the efficacy of donepezil in patients with mild to moderate $\mathrm{AD}$ was investigated $[22,23]$, a mean change in the MMSE score of 0.24 to 1.35 points with a difference from the change in the placebo groups of 1.02 to 1.36 points was reported. In contrast, in the confirmatory phase of this study and in the previous double-blind study [11] in patients with DLB, the mean change in the MMSE score in the active groups (5 or $10 \mathrm{mg}$ ) was 1.4 to 3.4 points with a difference from the placebo groups of 0.8 to 3.8 points, which exceeded the equivalent scores in the two AD studies. Therefore, these results imply that treatment with donepezil for DLB provides greater improvement in cognitive function than for AD, for which donepezil had already been approved, reinforcing the clinical significance of treating DLB with donepezil.

In the phase II study, donepezil clearly showed dosedependent efficacy against behavioral and neuropsychiatric symptoms [11]. In the present study, however, the placebo group also benefited from improvement in these symptoms, which represents the failure to replicate the findings in the previous study. Which factors affected the unexpected improvement of behavioral and neuropsychiatric symptoms in the placebo group? Two possible reasons are conceivable in terms of the time of the trials: (1) promotion of disease awareness and improved caregiving methodology brought about by quantitatively and qualitatively enriched disease-related information and (2) the emergence of reports on successful psychosocial interventions in behavioral and neuropsychological disorders 
related to DLB. Psychosocial factors, as well as brain organic and functional factors, have been reported to cause symptoms such as hallucinations in DLB [24]. Anxiety alleviation, accompanied by enhanced disease understanding, advancement in coping skills and promotion of empathic attitudes through disease education and instructions, may relieve symptoms (for example, frequency or severity of hallucinations) $[24,25]$. Most of the patients and their caregivers likely received disease education and/or caregiving instructions or acquired information on the disease and its care right before or during the study. The education of and information provided for caregivers may also have increased a positive bias, because NPI is an assessment scale implemented through interviews with caregivers. To lessen the placebo effect, a lead-in period when nonpharmacological treatment is administered has been suggested by a study in which investigators evaluated the efficacy of pimavanserin on psychosis in Parkinson's disease [26]. The results of our present study support our interpretation and the necessity of disease-specific brief psychosocial therapy in the lead-in period in future studies.

In the confirmatory phase, most of the AEs were mild or moderate in severity. The absence of substantial differences in the incidence of AEs or treatment-related AEs, and the existence of fewer reports on AEs that led to discontinuation in the $10 \mathrm{mg}$ group than in the placebo group, suggest tolerability of donepezil in patients with DLB. The incidence of gastrointestinal symptoms, which are typically observed AEs with ChEI administration, did not tend to increase in the active groups. Another expected risk was parkinsonism. Donepezil may possibly induce or exacerbate extrapyramidal symptoms, which are threatening for patients with DLB. Although it is reported with a slightly higher incidence in the $10 \mathrm{mg}$ group, none of these events were serious, and the UPDRS part III score did not represent significant deterioration in each of the active groups. We found no particular concerns about psychiatric symptoms or arrhythmia.

The interpretation of the present results requires taking some points into consideration. First, the number of patients enrolled by each center was generally small (that is, none by 14 of 72 centers and only 1 by 15 of the remaining 58), possibly due to DLB's characteristic features, including the faster progression, severe psychiatric symptoms and greater caregiver burden when compared to those with AD [4,27-30]. Similar recruitment difficulties impeded the previous phase II trial and a placebo-controlled study of rivastigmine in patients with DLB [31]. This may have caused a flaw in the interrater reliability of the clinical ratings. However, in this trial, a training and certification course was mandatory for the investigators. A second limitation is the short duration of the RCT phase. The period was set to 12 weeks, considering the above-noted disease-specific characteristics and the result of the previous phase II trial and its extension. The long-term efficacy of donepezil was evaluated in the open-label extension phase and is reported in another paper [13]. Third, because a global measure was not used, the influence of donepezil administration on the global clinical status cannot be inferred, despite its clinically important effect on improvement in cognitive function demonstrated through evaluation using the MMSE.

\section{Conclusions}

The predefined superiority of donepezil over the placebo in the co-primary endpoints was not confirmed. However, significant improvement in MMSE score was demonstrated with $10 \mathrm{mg}$ but not $5 \mathrm{mg}$. Overall, donepezil was well tolerated in patients with DLB. While paying careful attention to gastrointestinal and parkinsonian symptoms, patients with DLB can safely benefit from treatment with donepezil.

\section{Additional files}

Additional file 1: Cognitive Fluctuation Inventory (CFI). This

questionnaire was originally developed in Japanese. The English version is not yet validated.

Additional file 2: List of all institutional review boards.

\section{Abbreviations}

AD: Alzheimer's disease; AE: Adverse event; ANCOVA: Analysis of covariance; ChAT: Choline acetyltransferase; ChEl: Cholinesterase inhibitors; DLB: Dementia with Lewy bodies; FAS: Full analysis set; LOCF: Last observation carried forward; MMSE: Mini-Mental State Examination; NPI: Neuropsychiatric Inventory; PPS: Per-protocol set; RCT: Randomized placebo-controlled trial; SD: Standard deviation; SE: Standard error; UPDRS: Unified Parkinson's Disease Rating Scale; ZBI: Zarit Caregiver Burden Interview.

\section{Competing interests}

$\mathrm{Ml}$ received personal fees from Eisai during the conduct of the study; grants and personal fees from Daiichi Sankyo, Eisai, FUJIFILM RI, Janssen, Nihon Medi-Physics, Novartis, Pfizer, Takeda and Tsumura; and personal fees from MSD and Ono Pharmaceutical outside the submitted manuscript. All grants were for his department, and he received them as the director of the department. EM received personal fees from Eisai during the conduct of the study; grants and personal fees from Eisai, Janssen, Daiichi Sankyo, Nihon Medi-Physics and FUJIFILM Rl; and personal fees from Johnson \& Johnson, Lundbeck, Novartis, Ono and Medtronic outside the submitted manuscript. All grants were for his department, and he received them as the director of the department. KM and MN are employees of Eisai. KK received personal fees from Eisai during the conduct of the study and personal fees from Tsumura, Eisai, Janssen, FUJIFILM Rl, Novartis, Nihon Medi-Physics, Daiichi Sankyo, Ono, Otsuka and Dainippon Sumitomo outside the submitted manuscript.

\section{Authors' contributions}

$\mathrm{MI}$ and EM designed the study, analyzed the data and wrote the manuscript. KM designed the study and analyzed the data. MN designed and conducted the study. KK designed and supervised the study. All the authors read and approved the final manuscript.

\section{Acknowledgements}

We thank all patients and caregivers for their participation in the study; all investigators and their site staff for their contributions; and the Eisai study team (E Ebisawa, H Yamaguchi, H Yoshida, R Nagai, S Ishizaki and T Kobayashi) for their assistance. This study was sponsored by Eisai Co, Ltd (Tokyo, Japan). The sponsor was involved in the study design and the collection and analysis of 
data. The Donepezil-DLB Study Investigators (by whom subjects were enrolled): Yasuto Higashi (Himeji Central Hospital), Naoki Fujii (Omuta Hospital), Yoshiaki Aihara (Shinozuka Hospital), Daisuke Uematsu (Uematsu Neurological Clinic), Yasuhiro Tsugu (Toyokawa City Hospital), Akira Terashima (Hyogo Brain and Heart Center), Kiyohiko Kondo (Yoka Hospital), Hijiri Ito (Miyoshi Neurology Clinic), Rokuro Matsubara (Matsubara Hospital), Eizo Iseki (Juntendo Tokyo Koto Geriatric Medical Center), Koichi Okamoto (Gunma University Hospital), Yuichi Maruki (Saitama Neuropsychiatric Institute), Tomoyuki Ono (Takesato Hospital), Haruo Hanyu (Tokyo Medical University Hospital), Tomonobu Kato (Osaka Red Cross Hospital), Chigusa Watanabe (Hiroshima-Nishi Medical Center), Shinji Ouma (Fukuoka University Hospital), Takemi Kimura (Kikuti National Hospital), Hiroaki Kazui (Osaka University Hospital), Kazuya Okumura (Shirai Hospital), Mitsuhiro Tsujihata (Nagasaki Kita Hospital), Yoko Nakano (Sukoyaka-silver Hospital), Satoshi Orimo (Kanto Central Hospital), Masutaro Kanda (Takeda General Hospital), Yuri Kitamura (Nanohana Clinic), Chika Nishimura (Kurumi Clinic), Tadanori Hamano (University of Fukui Hospital), Chiaki Kudoh (Kudoh Chiaki Hospital), Noriko Kawashima (Kawashima Neurology Clinic), Yusaku Shimizu (Ina Central Hospital), Kuniko Ishikawa (Tenryu Hospital), Yuji Abe (MEDOC Medical Dock \& Clinic), Jun Ochiai (Nagoya Ekisaikai Hospital), Norio Taniguchi (Asakayama General Hospital), Yusaku Nakamura (Sakai Hospital Kinki University Faculty of Medicine), Yo Nishimura (Nishi-Kobe Medical Center), Koki Kikugawa (Tsubame Rosai Hospital), Kosuke Nishiyama (Yuge Hospital), Shin Tanaka (Mishima Hospital), Mikiko Kamijo (Chubu Rosai Hospital), Hideyuki Sawada (Utano Hospital), Kazunori Okahara (Keimei Memorial Hospital), Keiko Tokunaga (Ageo Central General Hospital), Masayuki Yokochi (Ebara Hospital), Yasuhiro Kawase (Kawase Neurology Clinic), Koichi Mizoguchi (Shizuoka Institute of Epilepsy and Neurological Disorders), Hiroki Kamada (Oe Hospital), Shogyoku Bun (Hospital Bando), Yasumasa Yoshiyama (Chiba-East Hospital), Tatsuru Kitamura (Takamatsu Hospital), Aki Nakanishi (Osaka City Kosaiin Hospital), Tsukasa Kusuki (Izumino Hospital), Hisashi Yonezawa (Iwate Medical University Hospital), Tsuyoshi Torii (Kure Medical Center), Koichi Mino (Kobe City Medical Center West Hospital), Mamoru Hashimoto (Kumamoto University Hospital), Aoi Yoshiiwa (Oita University Hospital) and Ayumi Okumura (Okumura Clinic).

\section{Author details}

'Department of Neuropsychiatry, Faculty of Life Sciences, Kumamoto University, 1-1-1 Honjo, Chuo-ku, Kumamoto 860-8556, Japan. ${ }^{2}$ Department of Behavioral Neurology and Cognitive Neuroscience, Tohoku University Graduate School of Medicine, 2-1, Seiryo-machi, Aoba-ku, Sendai, Miyagi 980-8575, Japan. ${ }^{3}$ Eisai Product Creation Systems, Eisai Co. Ltd, 4-6-10 Koishikawa, Bunkyo-ku, Tokyo 112-8088, Japan. ${ }^{4}$ Department of Psychiatry, Yokohama City University School of Medicine, 3-9 Fukuura, Kanazawa-ku, Yokohama, Kanagawa 236-0004, Japan.

Received: 28 April 2014 Accepted: 12 November 2014 Published online: 03 February 2015

\section{References}

1. McKeith I, Mintzer J, Aarsland D, Burn D, Chiu H, Cohen-Mansfield J, Dickson D, Dubois B, Duda JE, Feldman H, Gauthier S, Halliday G, Lawlor B, Lippa C, Lopez OL, Carlos MJ, O'Brien J, Playfer J, Reid W, International Psychogeriatric Association Expert Meeting on DLB: Dementia with Lewy bodies. Lancet Neurol 2004, 3:19-28.

2. McKeith IG, Galasko D, Kosaka K, Perry EK, Dickson DW, Hansen LA, Salmon DP, Lowe J, Mirra SS, Byrne EJ, Lennox G, Quinn NP, Edwardson JA, Ince PG, Bergeron C, Burns A, Miller BL, Lovestone S, Collerton D, Jansen EN, Ballard C, de Vos RA, Wilcock GK, Jellinger KA, Perry RH: Consensus guidelines for the clinical and pathologic diagnosis of dementia with Lewy bodies (DLB): report of the consortium on DLB international workshop. Neurology 1996, 47:1113-1124

3. Allan L, McKeith I, Ballard C, Kenny RA: The prevalence of autonomic symptoms in dementia and their association with physical activity, activities of daily living and quality of life. Dement Geriatr Cogn Disord 2006, 22:230-237.

4. McKeith IG, Rowan E, Askew K, Naidu A, Allan L, Barnett N, Lett D, Mosimann UP, Burn D, O'Brien J: More severe functional impairment in dementia with lewy bodies than Alzheimer disease is related to extrapyramidal motor dysfunction. Am J Geriatr Psychiatry 2006, 14:582-588

5. Lippa CF, Smith TW, Perry E: Dementia with Lewy bodies: choline acetyltransferase parallels nucleus basalis pathology. J Neural Transm 1999, 106:525-535.
6. Perry EK, Haroutunian V, Davis KL, Levy R, Lantos P, Eagger S, Honavar M, Dean A, Griffiths M, McKeith IG, Perry RH: Neocortical cholinergic activities differentiate Lewy body dementia from classical Alzheimer's disease. Neuroreport 1994, 5:747-749.

7. Perry EK, Irving D, Kerwin JM, McKeith IG, Thompson P, Collerton D, Fairbairn AF, Ince PG, Morris CM, Cheng AV, Perry RH: Cholinergic transmitter and neurotrophic activities in Lewy body dementia: similarity to Parkinson's and distinction from Alzheimer disease. Alzheimer Dis Assoc Disord 1993, 7:69-79.

8. Ballard C, Piggott M, Johnson M, Cairns N, Perry R, McKeith I, Jaros E, O'Brien J, Holmes C, Perry E: Delusions associated with elevated muscarinic binding in dementia with Lewy bodies. Ann Neurol 2000, 48:868-876.

9. McKeith IG, Dickson DW, Lowe J, Emre M, O'Brien JT, Feldman H, Cummings J, Duda JE, Lippa C, Perry EK, Aarsland D, Arai H, Ballard CG, Boeve B, Burn DJ, Costa D, Del Ser T, Dubois B, Galasko D, Gauthier S, Goetz CG, Gomez-Tortosa E, Halliday G, Hansen LA, Hardy J, Iwatsubo T, Kalaria RN, Kaufer D, Kenny RA, Korczyn A, et al: Diagnosis and management of dementia with Lewy bodies: third report of the DLB Consortium. Neurology 2005, 65:1863-1872.

10. O'Brien JT, Burns A, BAP Dementia Consensus Group: Clinical practice with anti-dementia drugs: a revised (second) consensus statement from the British Association for Psychopharmacology. J Psychopharmacol 2011, 25:997-1019.

11. Mori E, Ikeda M, Kosaka K, Donepezil-DLB Study Investigators: Donepezil for dementia with Lewy bodies: a randomized, placebo-controlled trial. Ann Neurol 2012, 72:41-52.

12. Ikeda M, Mori E, Kosaka K, Iseki E, Hashimoto M, Matsukawa N, Matsuo K, Nakagawa M, Donepezil-DLB Study Investigators: Long-term safety and efficacy of donepezil in patients with dementia with Lewy bodies: results from a 52-week, open-label, multicenter extension study. Dement Geriatr Cogn Disord 2013, 36:229-241.

13. Mori E, Ikeda M, Nagai R, Matsuo K, Nakagawa M, Kosaka K: Long-term donepezil use for dementia with Lewy bodies: results from an open-label extension of phase III trial. Alzheimers Res Ther, DOI 10.1186/s13195-014-0081-2.

14. Cummings JL: The Neuropsychiatric Inventory: assessing psychopathology in dementia patients. Neurology 1997, 48:S10-S16.

15. Cummings JL, Mega M, Gray K, Rosenberg-Thompson S, Carusi DA, Gornbein J: The Neuropsychiatric Inventory: comprehensive assessment of psychopathology in dementia. Neurology 1994, 44:2308-2314.

16. Hashimoto M, Manabe Y, Mori E, Hirono N, Kosaka K, Ikeda M: Content validity and inter-rater reliability of the Cognitive Fluctuation Inventory [Article in Japanese]. Brain Nerve 2014, 66:175-183.

17. Mori S, Mori E, Iseki E, Kosaka K: Efficacy and safety of donepezil in patients with dementia with Lewy bodies: preliminary findings from an open-label study. Psychiatry Clin Neurosci 2006, 60:190-195.

18. Hoehn MM, Yahr MD: Parkinsonism: onset, progression and mortality. Neurology 1967, 17:427-442.

19. Folstein MF, Folstein SE, McHugh PR: "Mini-Mental State": a practical method for grading the cognitive state of patients for the clinician. J Psychiatr Res 1975, 12:189-198.

20. Zarit SH, Reever KE, Bach-Peterson J: Relatives of the impaired elderly: correlates of feelings of burden. Gerontologist 1980, 20:649-655.

21. Fahn S, Elton R, UPDRS Development Committee: Unified Parkinson's Disease Rating Scale. In Recent Developments in Parkinson's Disease. Volume 2. Edited by Fahn S, Marsden CD, Calne DB, Goldstein M. New York: Macmillan Healthcare Information; 1987:153-163. 293-304.

22. Rogers SL, Doody RS, Mohs RC, Friedhoff LT: Donepezil improves cognition and global function in Alzheimer disease: a 15-week, double-blind, placebocontrolled study. Donepezil Study Group Arch Intern Med 1998, 158:1021-1031.

23. Rogers SL, Farlow MR, Doody RS, Mohs R, Friedhoff LT, the Donepezil Study Group: A 24-week, double-blind, placebo-controlled trial of donepezil in patients with Alzheimer's disease. Neurology 1998, 50:136-145.

24. Ota K, Iseki E, Murayama N, Fujishiro H, Kasanuki K, Chiba Y, Sato K, Arai H: Psychosocial risk factors for clinical symptoms in patients with dementia with Lewy bodies compared with Alzheimer's disease [Article in Japanese]. Jpn J Geriatr Psychiatry 2012, 23:457-465.

25. Ota K, Iseki E, Murayama N, Fujishiro H, Arai H, Sato K: Effect of psychological intervention for visual hallucinations in patients with dementia with Lewy bodies. Clin Psychiatry 2011, 53:845-853.

26. Cummings J, Isaacson S, Mills R, Williams H, Chi-Burris K, Corbett A, Dhall R, Ballard C: Pimavanserin for patients with Parkinson's disease psychosis: a randomised, placebo-controlled phase 3 trial. Lancet 2013, 383:533-540. 
27. Olichney JM, Galasko D, Salmon DP, Hofstetter CR, Hansen LA, Katzman R, Thal $\sqcup$ : Cognitive decline is faster in Lewy body variant than in Alzheimer's disease. Neurology 1998, 51:351-357.

28. Bostrom F, Jonsson L, Minthon L, Londos E: Patients with dementia with Lewy bodies have more impaired quality of life than patients with Alzheimer disease. Alzheimer Dis Assoc Disord 2007, 21:150-154.

29. Lee DR, McKeith I, Mosimann U, Ghosh-Nodyal A, Thomas AJ: Examining carer stress in dementia: the role of subtype diagnosis and neuropsychiatric symptoms. Int J Geriatr Psychiatry 2013, 28:135-141.

30. Rongve A, Vossius C, Nore S, Testad I, Aarsland D: Time until nursing home admission in people with mild dementia: comparison of dementia with Lewy bodies and Alzheimer's dementia. Int J Geriatr Psychiatry 2014, 29:392-398.

31. McKeith I, Del Ser T, Spano P, Emre M, Wesnes K, Anand R, Cicin-Sain A, Ferrara R, Spiegel R: Efficacy of rivastigmine in dementia with Lewy bodies: a randomised, double-blind, placebo-controlled international study. Lancet 2000, 356:2031-2036.

\section{Submit your next manuscript to BioMed Central and take full advantage of:}

- Convenient online submission

- Thorough peer review

- No space constraints or color figure charges

- Immediate publication on acceptance

- Inclusion in PubMed, CAS, Scopus and Google Scholar

- Research which is freely available for redistribution 